\title{
¿Hacia dónde debe ir el ICTOP-ICOM? Valoraciones de su conferencia anual
}

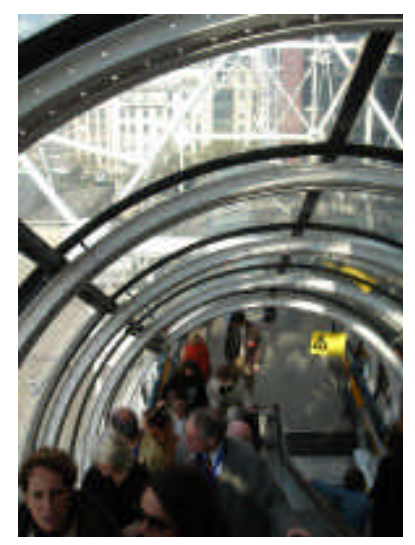

Participantes en la Conferencia anual del ICTOPICOM durante su visita al Centro Georges Pompidou
Entre el 19 y el 23 de octubre de 2005 se celebró en París, en la sede del Institut National du Patrimoine, la Conferencia anual del ICTOP-ICOM (international Committee for Training of Personnel). En esta ocasión el tema era "Formación y desarrollo profesional en los museos. Papel del ICTOP en un mundo globalizado", el cual fue tratado por 26 asistentes de 16 países de todo el mundo.

En la sesión inaugural se presentó no solamente el contexto museístico del país de acogida, sino que también se trató la importancia del ICOM en general y del comité del ICTOP dada su transversalidad dentro de la organización internacional y por su vocación. El ICTOP debe encargarse de la formación inicial y continua de las personas que trabajan o lo harán en un futuro en los museos, adecuando a esa formación las necesidades y el buen funcionamiento del museo actual y de la sociedad que lo envuelve.

Elizabeth Caillet, responsable del área de Eventos culturales y exhibición del Musée de l'Homme de París, hizo una reflexión sobre el concepto de museo, poniéndolo en cuestión a raíz de la evolución que éste ha sufrido en los últimos 25 años. Se han diversificado las actividades que ofrece, los tipos de patrimonio que se pueden encontrar, sus intereses políticos, económicos o de financiación, así como se han modernizado funciones antiguas gracias a la influencia de las nuevas tecnologías. El problema de la externalización de muchas de estas nuevas funciones ha provocada una progresiva pérdida de identidad y poder de los museos, con lo que es necesario desarrollar equipos profesionales que respondan a las competencias generales preestablecidas por organismos internacionales pero que a la vez sean adaptadas y modeladas a sus necesidades.

Nancy Fuller, de la Smithsonian Institution, planteó una sesión colaborativa en la que participaron los asistentes y en la que se definió el concepto de partnership, el por qué de su importancia, qué hacer para que sea positivo y cómo escapar en caso de que no funcione.

\section{Conclusiones}

De las presentaciones, discusiones y observaciones planteadas podemos sacar las siguientes conclusiones:

$>$ El concepto de museo está cambiando sumamente rápido. Quizá se tendría que trabajar como en otros comités, que consideran el concepto de museo de un modo mucho más amplio.

$>$ Hay un problema de entendimiento al referirnos a conceptos, nociones y descripciones de ciertos términos, en idiomas distintos. Se propone crear un glosario universal de términos para favorecer la comunicación entre los profesionales de distintos países y tradiciones culturales.

> La estandarización no tiene por qué ser sinónimo de uniformidad, sino referirse más bien a una visión general, una guía que se adaptase y moldease a cada situación en función del entorno, del contexto, de la diversidad o necesidad de cada comunidad.

$>$ Las instituciones patrimoniales se están multiplicando, por lo que deberíamos replantearnos los perfiles profesionales de las personas que tendrán que trabajar en ellas ya que no todos son, ni serán "trabajadores de museo" en el sentido clásico del término.

$>$ Si definiésemos las competencias, habilidades y responsabilidades de los profesionales que deberían llevar a cabo tareas en una institución cultural o colección de una forma general, cualitativa y no cuantitativa, y sin asignarles nombres concretos, quizá facilitaríamos el trabajo a la hora de saber de qué 0 de quién estamos hablando.

$>$ La constitución del Espacio Europeo de Educación Superior supone una novedad a la vez que provocará grandes cambios. Esta adaptación ha provocado en el mundo universitario replanteamientos de muchas cuestiones y temas relacionados con esta institución, por lo que sería interesante aunar esfuerzos y trabajar conjuntamente universidad, museo/ instituciones patrimoniales y comi tés 0 asociaciones profesionales.

> También se planteó el "boom" del número de cursos de especialización, que ha pasado de 30 a casi 600, en menos de 20 años, en todo el mundo. Esto tendría que ser algo positivo si no fuera porque están surgiendo sin ningún tipo de asesoramiento por parte de este comité ni de profesionales ampliamente preparados y especializados, y sin adaptación a las necesidades del momento.

El papel del ICTOP se está replanteando, tendría que cambiar, adaptarse y anticiparse a las necesidades, a los nuevos tiempos, quizá tendría que trabajar de forma nueva y distinta, quizá cambiar de nombre... Algunos consideramos que debería adelantarse a los acontecimientos y definir cómo tendría que ser el profesional del siglo XXI y convertirse en un comité de referencia. Quizá convertirse en una organización a la que acudir para debatir y asesorar en temas de formación profesional en el campo no solamente museístico, sino cultural en general. ¿Hacia dónde ir? Ésta es la cuestión.

Anna Vié Riba

Departamento de Arte

Universidad Autónoma de Barcelona 